\title{
HABITAT SUITABILITY INDEX (HSI) MODEL OF PUNJAB URIAL (OVIS VEGNEI PUNJABIENSIS) IN PAKISTAN
}

\author{
S. Suleman ${ }^{* 1}$, W. A. Khan ${ }^{1}$, K. M. Anjum ${ }^{1}$, W. Shehzad ${ }^{2}$ and S. G. M. Hashmi ${ }^{1}$ \\ ${ }^{1}$ Department of Wildlife \& Ecology, University of Veterinary \& Animal Sciences, Lahore, Pakistan. \\ ${ }^{2}$ Institute of Biochemistry \& Biotechnology, University of Veterinary \& Animal Sciences, Lahore, Pakistan. \\ Corresponding author's email: saharsuleman59@gmail.com
}

\begin{abstract}
Unprecedented losses in biodiversity due to habitat loss and fragmentations in the current era have not only alarmed the scientists worldwide but also urged the need to devise suitable conservation strategies which are impossible without understanding the habitat requirements of the concerned species. Among many conservational methods Habitat suitability models are effective for identification of potential habitat and its relationship with the species. Punjab Urial is an endangered mammalian species of Kala Chitta Range and Salt Range in the Punjab, Pakistan. Maxent model was applied to identify the potential habitat by applying 120 sighting point, topographical and current bioclimatic variables. Possible area under receiver operating characteristics curves (AUC) test for current prediction is 0.988 that shows significant correlation between testing points and variables. In Pakistan total $3477 \mathrm{~km}^{2}$ area is suitable for Punjab Urial and potential habitats lie in limited areas in Rawalpindi, Sargodha, Gujrat, Mardan, Swabi, Nowshera, North Wziristan, Bannu, Dera Ismail Khan, Laki-Marwat and some area in Azad Jammu \& Kashmir. Habitat of Punjab Urial is shrinking due to certain reasons including habitat fragmentation. In-situ and Ex-situ techniques are the major recommendation for species conservation in suitable and potential habitat of Punjab Urial.
\end{abstract}

Key words: HSI model; Kala Chitta Range; Maxent; Punjab Urial; Salt Range.

\section{INTRODUCTION}

As a result of urbanization and deforestation of forest lands, different species of flora and fauna are being lost that has alarmed the biologists to protect the near extinction specie by preserving their habitats (Gazetteer, 1990). There are several environmental variables which are associated with species distribution and abundance and also contribute for the species preservation (Debinski et al., 1999).

Habitat study has key importance for the development of wildlife conservation policies, evaluation and conservation (Gerrard et al., 2001). Ecological studies such as; Habitat Suitability models provide plenty of knowledge about the relationships of wildlife with habitats and potential habitat identification (Van and Wiens, 1991; Verner et al., 1986). Among many conservative methods related to ground-based studies for conservation and management of habitats, habitat mapping is the most effective method (Lamprey, 1963) but actually in practice the whole calculation of habitat of a species especially for those having large distribution range is impossible. The application of satellite remote sensing technique is being widely used for accurate and quick attributes estimations (Kamat, 1986; Panwar, 1986). Geographical Information System (GIS) is one of the tools that can be used by wildlife managers and conservationists to manage and interpret a large amount of spatial data for conservation and management of species protection area (Vincenzi et al., 2006). The use of GIS in wildlife habitat conservation allows development of database of large quantity and performs analysis through evaluation and assessment for present as well as for future scenarios. Habitat suitability models not only help in assessment of habitat but also provide alternative habitat for conservational strategies. These models describe the species relationship with their habitat on the basis of research studies, previous knowledge and literature review (Brooks, 1997).

Among other endangered faunal species, Punjab Urial (Ovis vignei punjabiensis) the major mammalian game animal of Kala Chitta Range and Salt Range is also endangered and efforts are being made to conserve it in its distribution range. Punjab Urial is prevalent in the northern Punjab (Schaller, 1977; Schaller and Mirza, 1974) that is typically related with low round stony hills which are spotted with Accacia modesta and Olea ferruginea (Roberts, 1997). In addition to hunting and poaching, Punjab Urial is usually prized as a pet (Awan, 2006; Aleem, 1977; Frisina et al., 2001; Mirza et al., 1980; Roberts, 1997). Further, its habitats have been disturbed in past and ran to noticeable decrease in restriction therefore, the present study was devised to 
ascertain and evaluate the potential habitats of the species through species distribution modeling (SDM). 


\section{MATERIALS AND METHODS}

An area of $8803 \mathrm{~km}^{2}$ in six districts of Pakistan was visited for the assessment of distribution and habitat of Punjab Urial. The study area was located in Mianwali, Khushab, Chakwal, Kohat, Jehlum and Attock districts. These areas lies in Salt range (between 32०41" to 32056"N and $71^{\circ} 50^{\prime \prime}$ to $74^{\circ} \mathrm{E}$ ) and Kala Chitta Range (between $33^{\circ} 42^{\prime \prime} \mathrm{N}$ to $34^{\circ} 32^{\prime \prime} \mathrm{N}$ and $71^{\circ} 41^{\prime \prime E}$ to $72^{\circ} 56^{\prime \prime N}$ ) (Arshad $e t$ al. 2014). Major forest type in the study area was dry sub-tropical semi evergreen scrub forest (Figure 1).

All the potential habitats spotted in literature and proposed by officials of Punjab wildlife \& parks department, WWF-Pakistan and local hunters were evaluated during 24 field surveys. After confirmation of species presence, geographical coordinates were recorded with GPS receiver (Garmin map 76) from each site. GIS laboratory at Department of Wildlife and Ecology, UVAS was used for the field data assimilation.

A total of 120 sighting points (Figure 1) and two types of variables i.e. topographical (Digital Elevation Model (DEM), Slope, aspect), and current bioclimatic variables (Temperature, precipitation, slope, aspect, land cover and mask) were used for Maxent (Maximum entropy) modeling. DEM layer was downloaded from Shuttle Radar Topography Mission (SRTM) website. Spatial analysis tool of ArcGIS 10.5 was used to extract the slope and aspect from DEM and converted in to World Geodetic System (WGS) 1984 Universal Transverse Mercator (UTM) zone 42 North. The current bioclimatic variable data was downloaded from Worldclim website for the study area with a spatial resolution of $1 \mathrm{Km}$. DEM (Digital Elevation Model), slope and aspect were combined to $1 \times 1 \mathrm{~km}$ pixel size to align the dataset with bioclim datasets. All layers were converted to ASCII (American Standard Code for Information Interchange) format by using model builder function of ArcGIS (Ashraf et al., 2016). The detailed methodology for the prediction about the distribution of Punjab Urial is shown in Figure 2. The Maxent model was applied for current prediction with all variables to find out the most contributing with an option of 15 replicates. All the variables used in Maxent model are listed in table (1)

For the prediction of suitable habitat of the species, the Maxent work based on available secondary data. Maxent 3.3.3k version was used with random seed option with 5000 iterations and $20 \%$ of test sample size. To check the model accuracy Jacknife test, Area under curve with training and test data were calculated. Species distribution map was developed by converting ASCII outputs to raster. Raster was reclassified to calculate the area (Ashraf et al., 2016).

\section{RESULTS}

The relative contribution of each variable for Punjab Urial prediction is shown in the results of Jackknife test from Maxent (Figure 3a). For the prediction of potential habitat of Punjab Urial major contributing environmental variables were Precipitation of Warmest Quarter (bio18), Precipitation Seasonality (bio15), Precipitation of Driest Quarter (bio17), Land cover (LC25) and Precipitation of Wettest Quarter (bio16) that contributes $39.9 \%, 15.9 \%, 14.2 \%, 14.1 \%$ and $5.7 \%$ respectively (Table 1). Precipitation of Warmest Quarter (bio18), Annual Mean Temperature (bio1), Precipitation of Driest Quarter (bio17), Precipitation of Wettest Month (bio13), precipitation of driest Month (bio14), Iso-thermality (bio23) and DEM are the major contributing factors as they have higher AUC values (Figure 3b).

By applying Maxent model possible area under receiver operating characteristics curves (AUC) test for current prediction is 0.988 . The results of AUC values ( $<$ $0.9)$ shows high significance of our results (Figure $4 \mathrm{~b}$ ).

For current prediction total calculated suitable area for Punjab Urial from present bioclimatic is approximately $3477 \mathrm{~km}^{2}$ that is $0.41 \%$ of the total study area. By Using Maxent results Punjab Urial distribution maps were developed that are categorized into three classes which are highly suitable $(0.45-0.87)$ moderately suitable (0.18-0.44) and non-suitable (0-0.17) (Figure. 6; Table. 2).

On the basis of the Maxent model results, it was found that highly suitable areas for Punjab Urial was present in Attock, Jehlum, Chakwal, Khushab, Mianwali, Kohat, Dera Ismail Khan, Karak and Nowshera districts. While limited areas in Rawalpindi Sargodha, Gujrat, Mardan Swabi, Haripur, North Wziristan, Bannu, Laki Marwat and some area in Azad Kashmir i.e. Bhimber and Mirpur has some probabilities to own the species (Figure 5 ; 6). All the most suitable areas for Punjab Urial were present up to $1500 \mathrm{~m}$ elevation with steppe mountains of low ranges and broken hills. These were dry sub-tropical areas with semi evergreen scrub forest. 


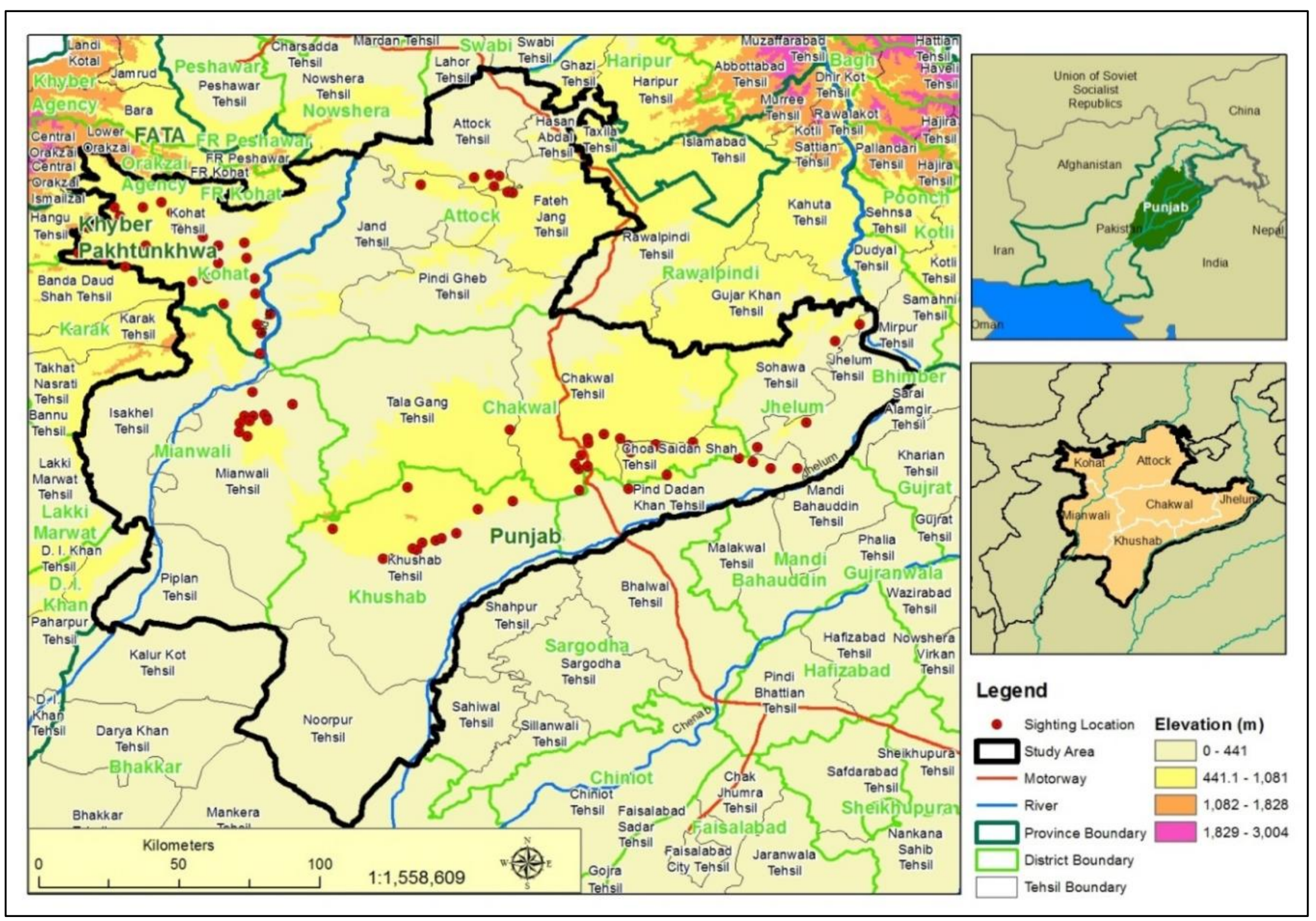

Figure 1. Current distribution of Punjab Urial in Pakistan 


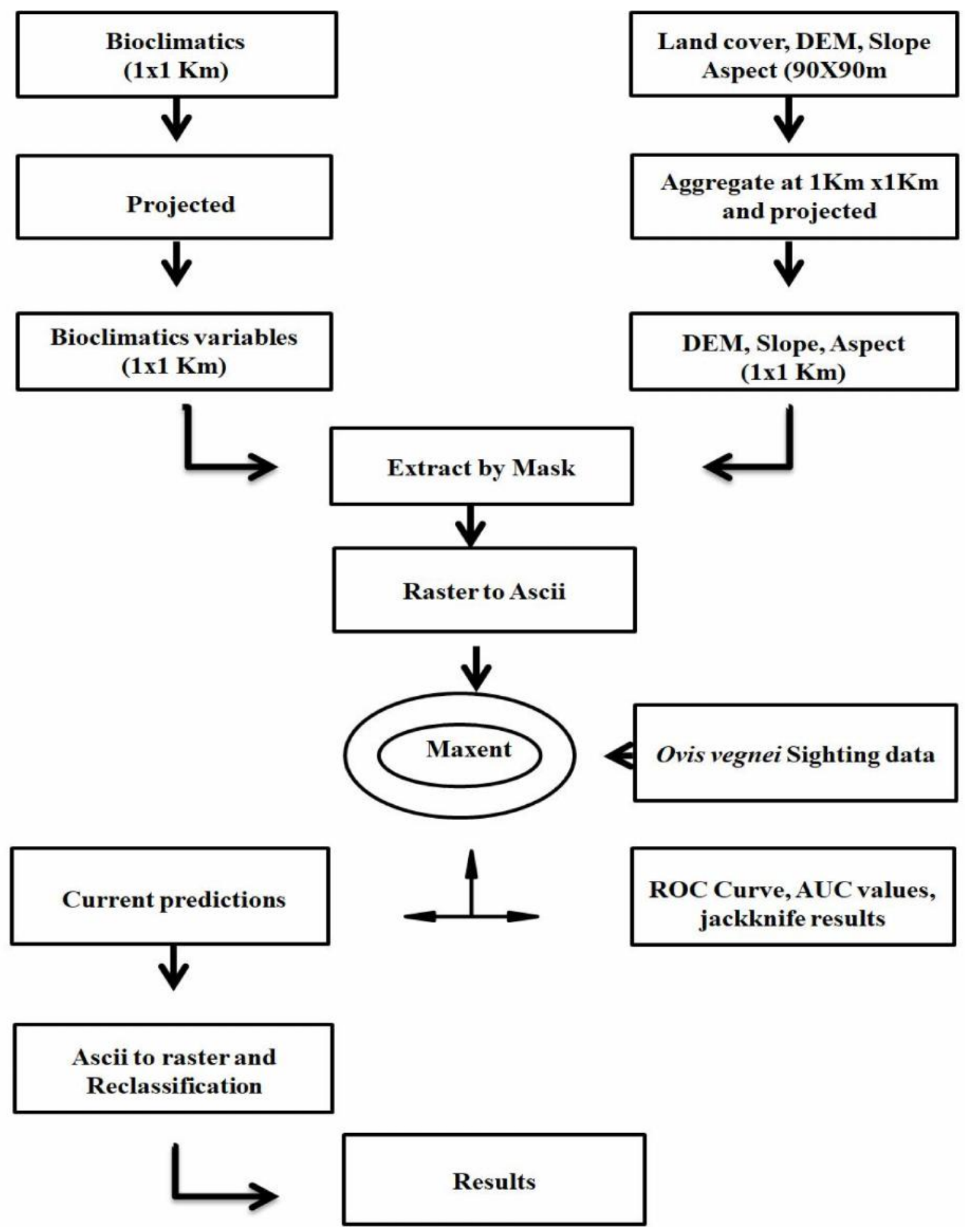

Figure No. 2. Maxent HSI Procedure 


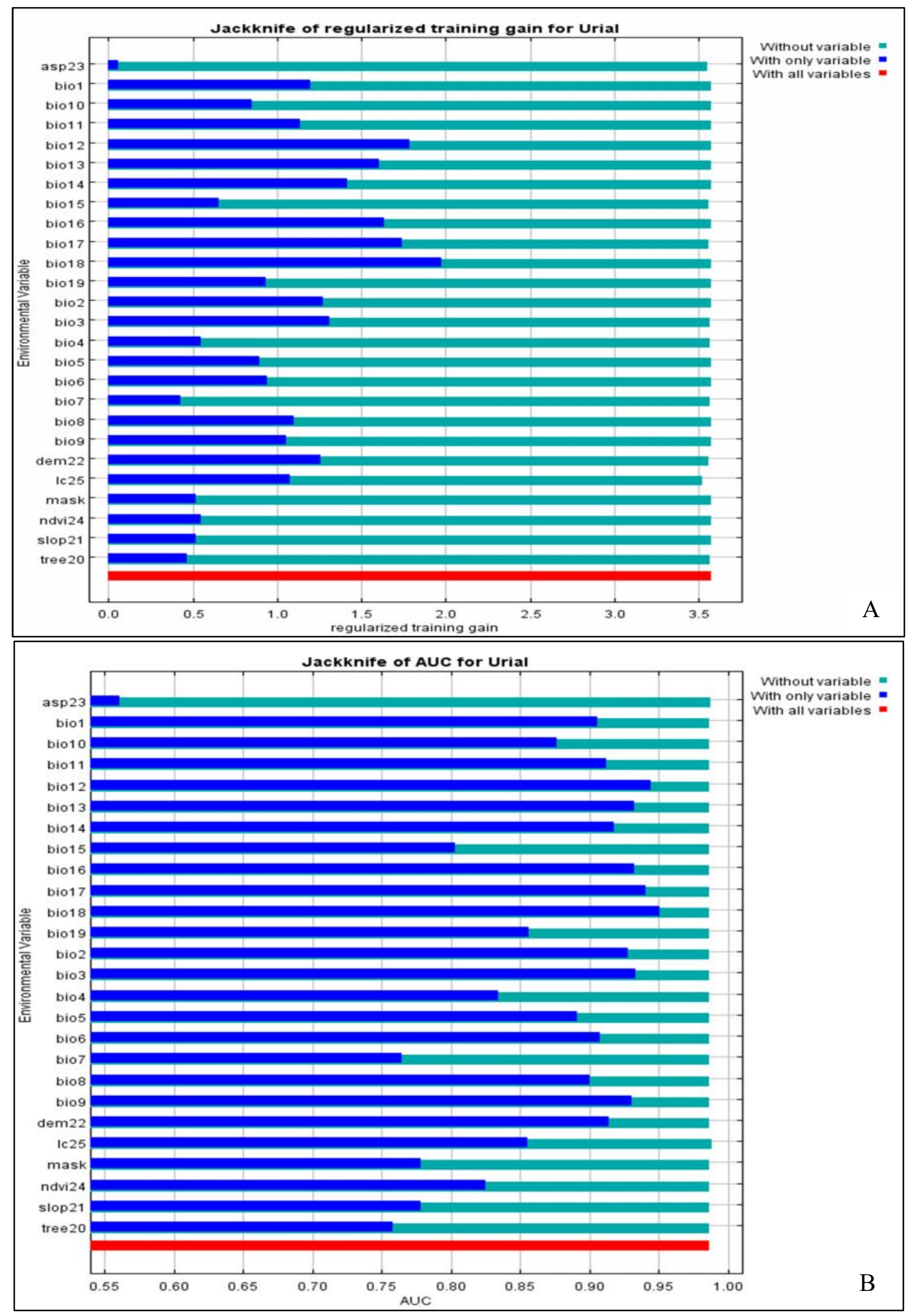

Figure 3. Jacknife of regularized training gain (a) and area under curve (AUC) (b) for Punjab Urial 


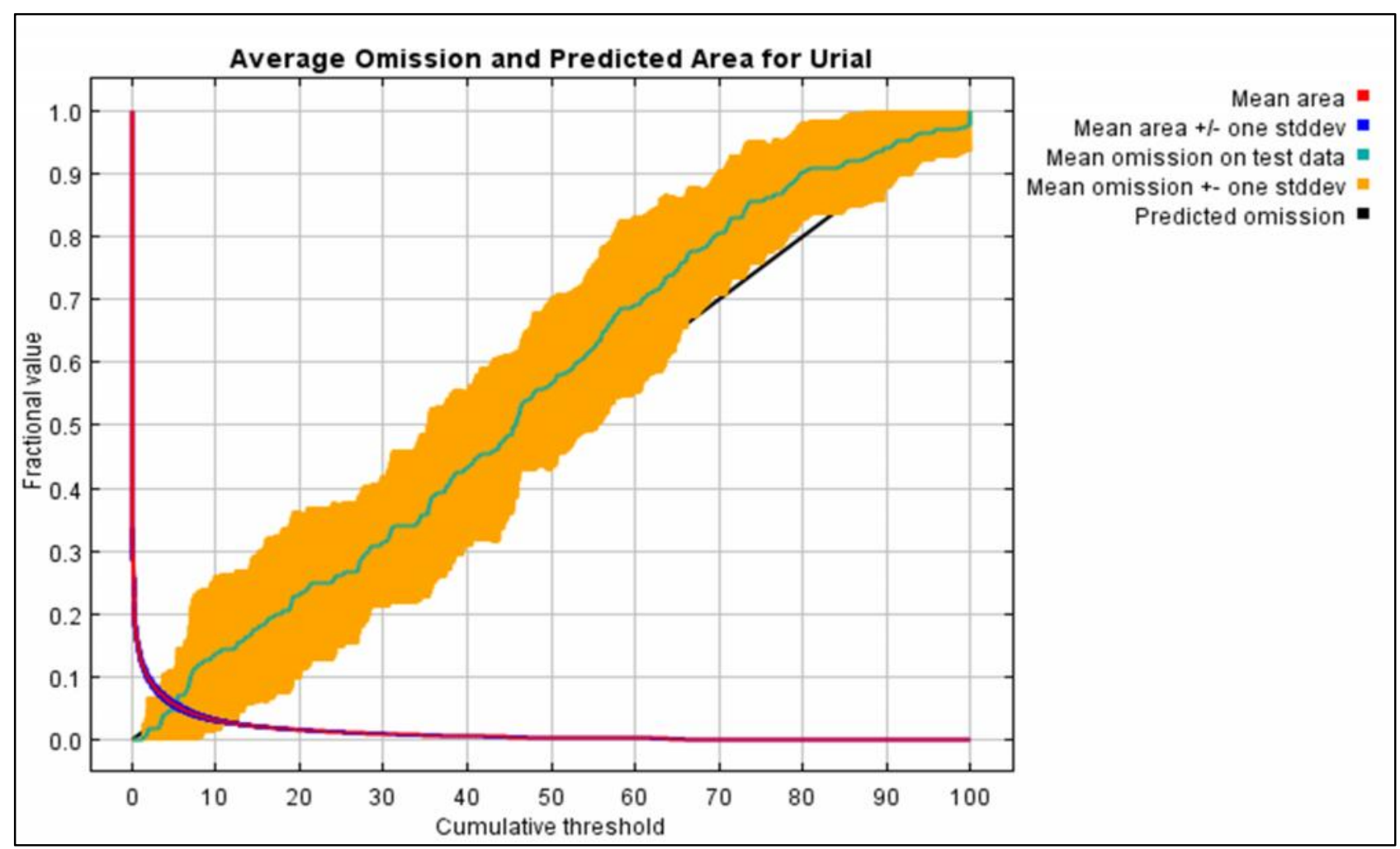

(a)

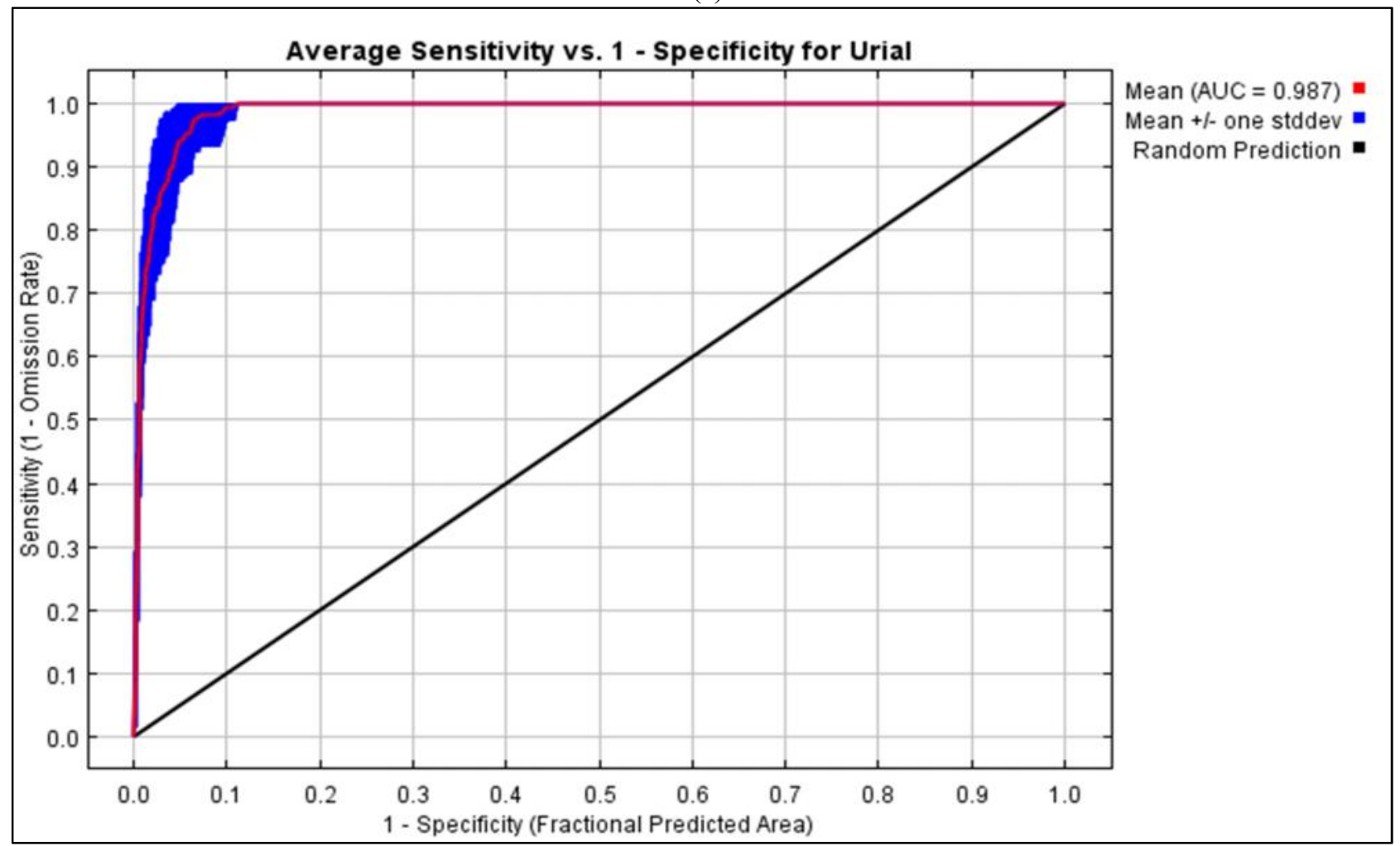

(b)

Figure 4. (a) Average Omission and Predicted Area; (b) Receiver Operating Characteristic (ROC) curve for Punjab Urial prediction 


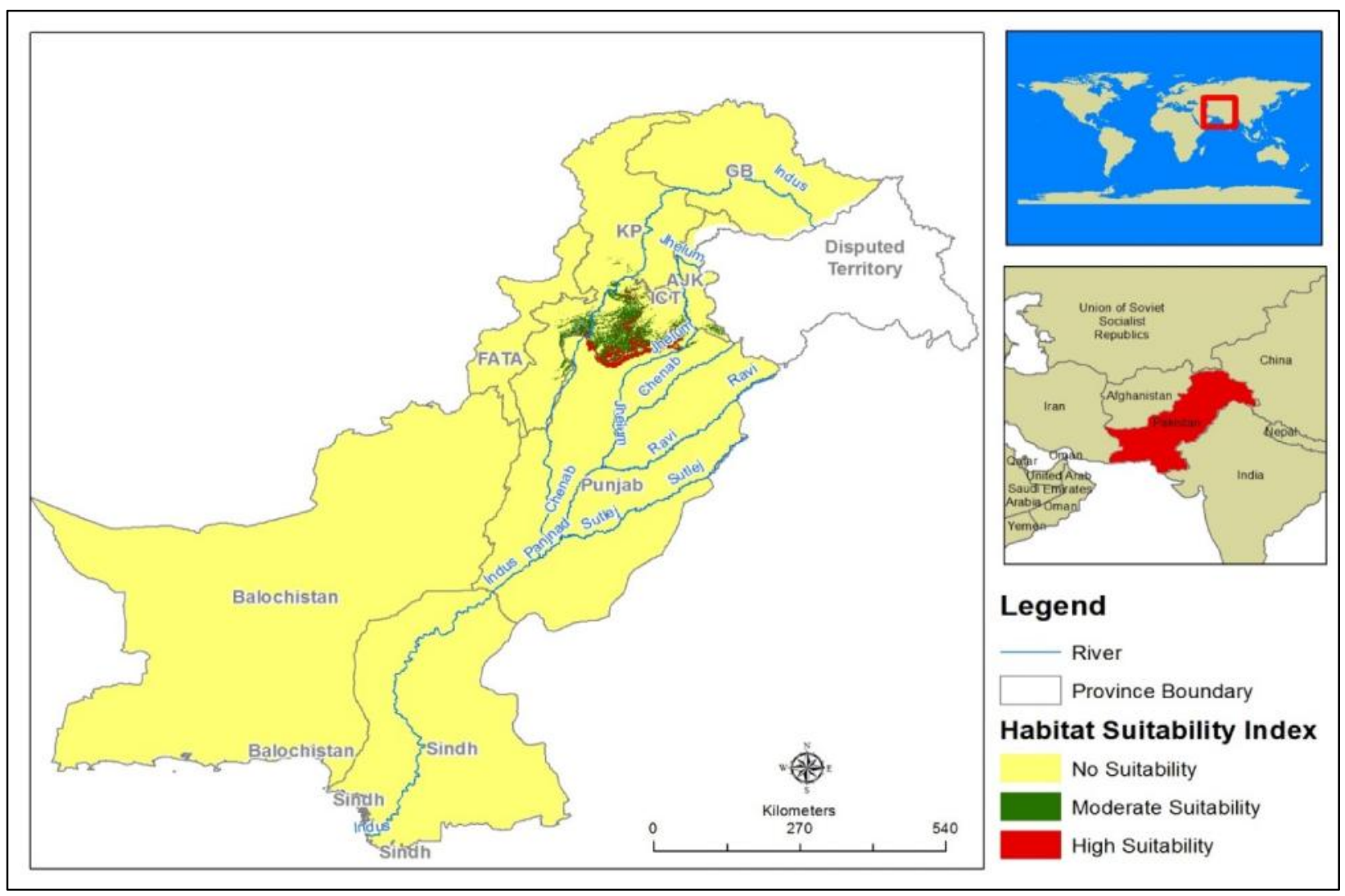

Figure No. 5: Habitat Suitability Index for Punjab Urial

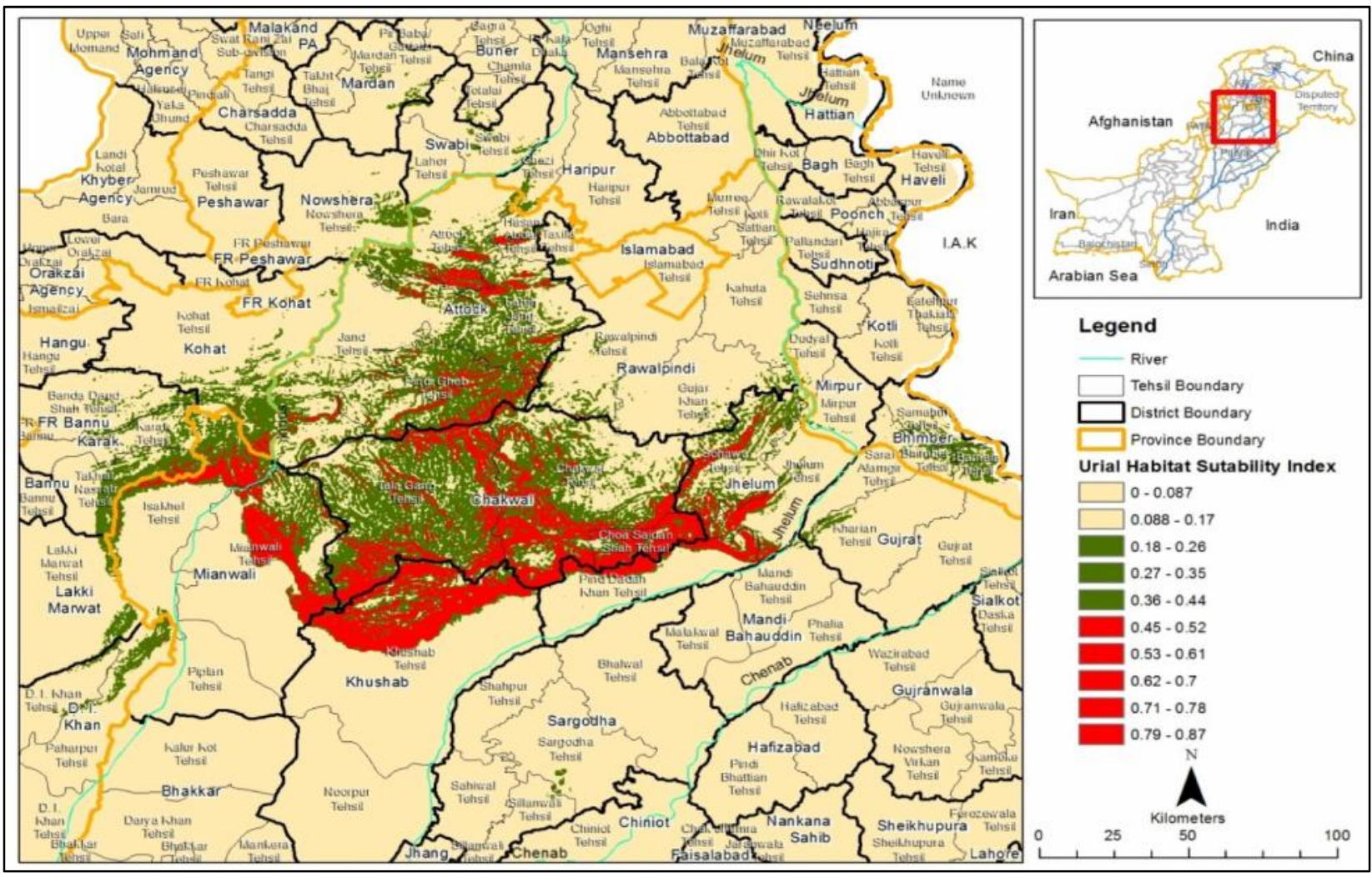

Figure No. 6: Habitat Suitability Index for Punjab Urial 


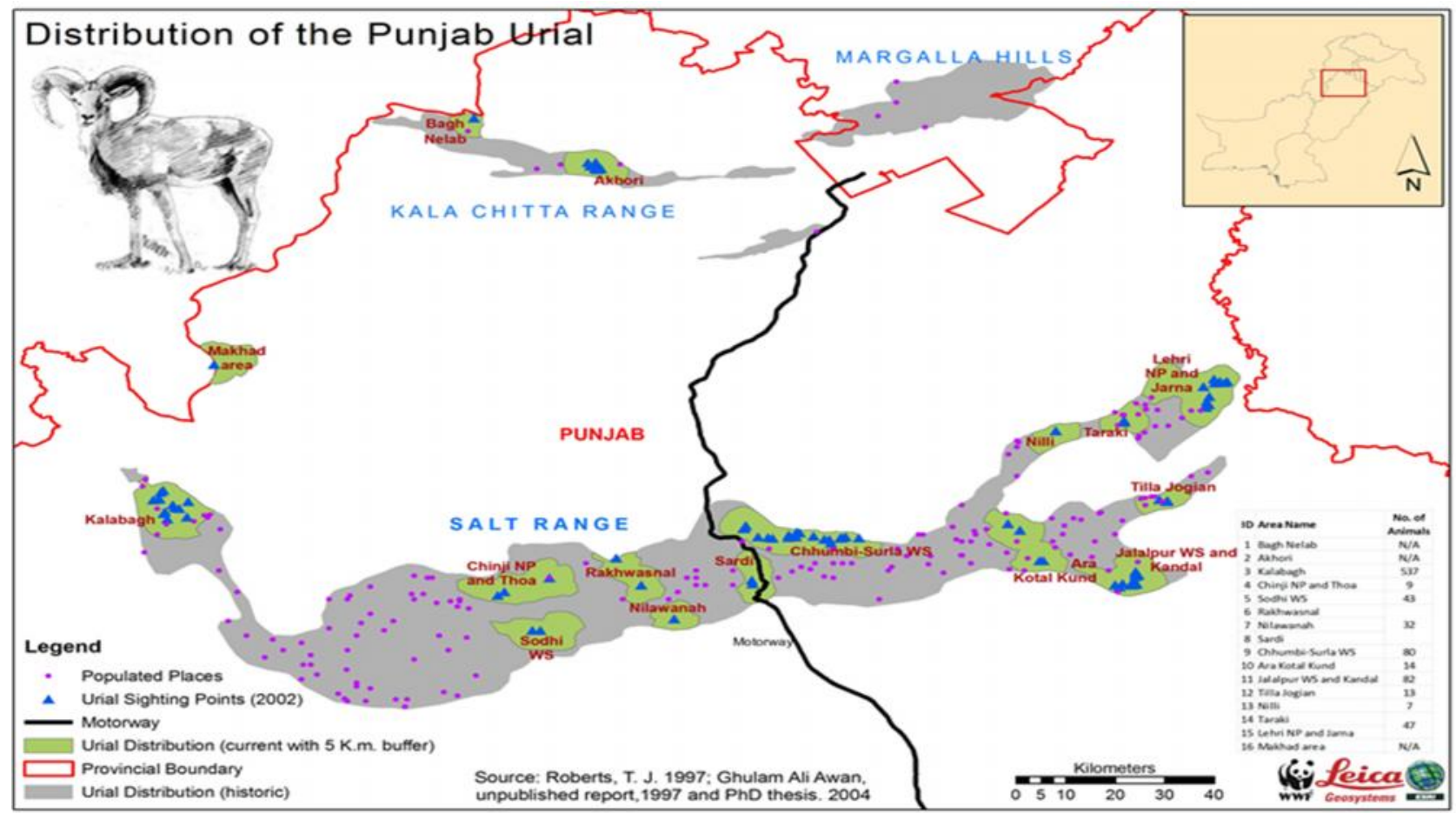

Figure No. 7: Historical distribution of Punjab Urial in Pakistan (c) WWF Pakistan

Table 1. Percentage contribution of used variables.

\begin{tabular}{cclcc}
\hline Sr. No. & Variable & \multicolumn{1}{c}{ Variable name } & $\begin{array}{c}\text { Percent } \\
\text { contribution }\end{array}$ & $\begin{array}{c}\text { Permutation } \\
\text { importance }\end{array}$ \\
\hline 1 & BIO1 & Annual Mean Temperature & 0.2 & 0 \\
2 & BIO3 & Isothermality (BIO2/BIO7)(* 100) & 0.1 & 12.2 \\
3 & BIO4 & Temperature Seasonality (SD *100) & 0.1 & 12.7 \\
4 & BIO5 & Max Temperature of Warmest Month & 0.3 & 11.4 \\
5 & BIO7 & Temperature Annual Range (BIO5-BIO6) & 0.1 & 9.4 \\
6 & BIO13 & Precipitation of Wettest Month & 0.1 & 2.3 \\
7 & BIO14 & precipitation of driest Month & 0.3 & 2.3 \\
8 & BIO15 & Precipitation Seasonality & 14.2 & 2.6 \\
9 & BIO16 & Precipitation of Wettest Quarter & 5 & 7.5 \\
10 & BIO17 & Precipitation of Driest Quarter & 14.1 & 16.6 \\
11 & BIO18 & Precipitation of Warmest Quarter & 39.9 & 0.8 \\
12 & BIO19 & Precipitation of Coldest Quarter & 0.4 & 0.3 \\
13 & Tree20 & Tree & 0.9 & 0.2 \\
14 & Slop21 & Slope & 0.2 & 0.5 \\
15 & Dem22 & & 1.1 & 7 \\
16 & ASP23 & Aspect & 0.8 & 0.3 \\
17 & LC25 & Land Cover & 5.7 & 3.1 \\
18 & Mask & & 15.9 & 10.5 \\
\hline
\end{tabular}

Table. 2. Suitable area for Punjab Urial distribution in Pakistan.

\begin{tabular}{clccc}
\hline Sr. No. & Suitability & Threshold & Current prediction $\left.\mathbf{( K m}^{2}\right)$ & Percentage \\
\hline 1 & Highly suitable area & $0.44-0.87$ & 3477 & $0.41 \%$ \\
2 & Moderately suitable area & $0.18-0.44$ & 10945 & $1.27 \%$ \\
3 & Non-suitable area & $0-0.17$ & 843229 & $98.32 \%$ \\
& Total & $0-0.87$ & 857651 & $100 \%$ \\
\hline
\end{tabular}




\section{DISCUSSION}

Phyto-geographically and physio-graphically, Pakistan has diversified and unique flora and fauna due to the Palearctic and Indomalayan elemental mixing (Gazetteer, 1990). Among three representatives of Ovis vignei; the Ovis vignei punjabensis (Punjab Urial) is the most important game species in Pakistan in general and in Punjab in particular because it is endemic and native to Kala Chitta Range and Salt Ranges area of Pakistan (Roberts, 1997).

Currently the Punjab Urial is present in only those areas which are highly suitable. These areas lie in six districts of Pakistan: Attock (Iqbal et al., 2012; Hussain et al., 2015), Kohat (Ayaz et al., 2012), Mianwali (Awan et al., 2004), Chakwal (Maan and Chaudhary, 2001; Hussain et al., 2015), Jehlum (Hussain et al., 2015; Habiba et al., 2015; Arshad and Hussain, 2018) and Khushab (Khan et al., 2015). On the basis of the model applied during the current studies, it was found that habitat types in Rawalpindi, Sargodha, Gujrat, Mardan, Swabi, Nowshera, Haripur, Karak, North Wziristan, Bannu, Dera Ismail Khan, Laki Marwat and some area in Azad Kashmir i.e. Bhimber and Mirpur have probabilities to own the species. Historical distributional studies describes that Punjab Urial population was viable in Bannu, North Wziristan (Malik 1987), Koho-i-Murat, Khair-i-Murat, Peshawar (Awan et al. 2004), Dera Ismail Khan, Laki Marwat (Malik, 1987) and Kashmir (Ward, 1928), but now no more population is present in these area that might be due to habitat degradation and over hunting. Distribution range of the species has been declined about 70\% since 1976 (Awan et al., 2004). The comparative analysis of current and historical distribution map clearly shows that habitat of the species is shrinking (Arshad and Hussain, 2018) (Figure 1; 7).

Although there are many operational conservational programs, practices and designated protected areas for the conservation of declining population, but on the basis of our model prediction population should be reintroduced in the probable habitat as the Ex-situ and In-situ techniques that can give a major solution about the conservation of species. The result of this study will help in formulating recommendations for the wildlife authorities to effectively conserve and manage the endangered Punjab Urial population using geospatial techniques.

\section{REFERENCES}

Aleem, A. (1977). Punjab Urial in Chak Jabbi area-Kala Chitta Range Range. Pakistan J. For. 27: 130138.
Arshad, M., M. Ahmad, E. Ahmed, A. Saboor, A. Abbas, and S Sadiq. (2014). An ethnobiological study in Kala Chitta Range hills of Pothwar region, Pakistan: multinomial logit specification. J. ethnobiol. ethnomed. 10(1):13.

Arshad, M.I. and A. Hussain. (2018). Population density estimates of Punjab Urial in Scrub forest. Pakistan J. Sci. Ind. Res. Ser. B: Boil. Sci. 61B (2): 95-102.

Ashraf, U., H. Ali, M. Chaudry, I. Ashraf, A. Batool, and Z. Saqib. (2016). Predicting the potential distribution of Olea ferruginea in Pakistan incorporating climate change by using maxent model. Sustainability. 8(8): 722.

Awan, G.A., T. Ahmad, and A. Salman. (2004). On the distribution of Punjab urial (Ovis vignei punjabiensis). Rec. Zool. Surv. Pakistan. 15: 16.

Awan, G.A. (2006). Conservation of Punjab urial (Ovis vignei punjabiensis) through long-term monitoring of marked individuals. A report to the The Rufford Maurice Laing Foundation, London, UK. 1-22.

Ayaz, S., A. Muhibullah, M. Jamil, M. Khan, and M. Qamar. (2012). Behaviour and biology of Ovis Orientalis (Urial) in Kotal Wild Life Park and Borraka Wildlife Sanctuary Kohat. The J. Anim. Plant. Sci. 22: 29-31.

Brooks, R.P. (1997). Improving habitat suitability index models. Wildl. Soc. Bull. 25: 163-167.

Maan, M.A. and A.A. Chaudhary. (2001). Wildlife diversity in Punjab (Pakistan). J. Bio. Sci. 1: 417.

Debinski, D., K. Kindscher, and M. Jakubauskas. (1999). A remote sensing and GIS-based model of habitats and biodiversity in the Greater Yellowstone Ecosystem. Int. J. Remote. Sens. 20: 3281-3291.

Frisina, M.R., M.H. Woodford, and G.A. Awan. (2001). Status of the Punjab urial (Ovis orientalis [vignei] punjabiensis) population in the Kalabagh, Salt Range of Punjab Province, Pakistan. A report to the United States Fish and Wildlife Service.

Gazetteer, K. (1990). Gazetteer of Kohat district, 188384. Reprinted by Sang-e-Meel publications Lahore. p. 186.

Gerrard, R., P. Stine, R. Church, and M. Gilpin. (2001). Habitat evaluation using GIS: A case study applied to the San Joaquin Kit Fox. Landsc. Urban. Plan. 52: 239-255.

Habiba, U., M. Anwar, I. Hussain, and M. Rais. (2015). Population density and habitat status of Punjab urial (ovis vignei punjabiensis) in diljabbadomeli game reserve, Punjab Pakistan. The J. Anim. Plant. Sci. 25(3): 650-655. 
Hussain, I., M. Munir, and M. Anwar. (2015). Food Habits of Punjab Urial, Ovis vignei punjabiensis. Lydekker, 1913, in Chumbi Surla Wildlife Sanctuary, Chakwal, Pakistan. Acta. Zool. Bulg. 67(4): 507-514.

Iqbal, M., M. Z. Saleem, M. A. Khan, M. Akhtar, and K. Mahmood. (2012). Urial (Mammalia, Bovidae, Caprini) from the Kala Chitta Range of Northern Pakistan. Punjab Univ. J. Zool. 27(2): 61-73.

Kamat, D.S. (1986). An integrated approach to remote sensing studies for wildlife habitat evaluation. Proceedings of seminar-cum-workshop on wildlife habitat evaluation using remote sensing techniques, Dehradun. p. 165-182.

Khan, W.A., M.S. Ahmed, A. Yaqub, H. Ali, and M. Arshad. (2015). Distribution and population status of Punjab urial, Ovis vignei punjabiensis (Mammalia: Bovidae), in Soan valley, Salt Range, Punjab, Pakistan. The J. Anim. Plant. Sci. 25(3): 666-671.

Lamprey, H. (1963). Ecological separation of the larg mammal species in the Trangire Game reserve, Tanganyika1. Afr. J. Ecol. 1: 63-92.

Malik, M.M. (1987). Management plan for wild artiodactyls in North West Frontier Province, Pakistan. Graduate thesis. University of Montana. P. 116-128.

Mirza, Z., M. Aslam, M. Asghar, and A. Mehal (1980). Distribution, status, habitat and food of the Urial in the Punjab. J. Bombay. Nat. Hist. 76: 423430 .

Robert, T.J. (1966). Ovis Orientalis punjabiensis. J. Bombay. Nat. History. Soc. 63(3): 746.

Roberts, T.J. (1997). The mammals of Pakistan (revised ed.) oxford university press. Karachi, Pakistan. 525 .
Schaller, G.B. (1977). Mountain monarchs. Wild sheep and goats of the Himalaya. University of Chicago Press.

Schaller, G.B. and Z.B. Mirza (1974). On the behaviour of Punjab urial (Ovis orientalis punjabiensis). The behaviour of ungulates and its relation to management. International Symposium held at the University of Calgary, Alberta, Canada, 2-5 November 1971. 1: 306-323.

Panwar, H.S. (1986). Forest cover mapping for planning tiger corridors between Kanha and Bandhavgarh - a proposed project. Proceedings of seminar-cum-workshop wildlife habitat evaluation using remote sensing techniques, IIRS Dehradun. p. 209-212

Van, H.B. and J.A. Wiens (1991). Forest bird habitat suitability models and the development of general habitat models. Colorado State Univ Fort Collins.

Verner, J., M.L. Morrison, and C.J. Ralph. (1986). Wildlife 2000: modeling habitat relationships of terrestrial vertebrates: based on an international symposium held at Stanford Sierra Camp, Fallen Leaf Lake, California, 7-11 October 1984. University of Wisconsin Press.

Vincenzi, S., G. Caramori, R. Rossi, and G. A. De Leo. (2006). A GIS-based habitat suitability model for commercial yield estimation of Tapes philippinarum in a Mediterranean coastal lagoon (Sacca di Goro, Italy). Ecol. Model. 193: 90104.

Ward, A.E. (1928). The mammals and birds of Kashmir and the adjacent hill provinces. J. Bombay. Nat. Hist. 29: 879-887. 